\title{
OSH - sustainability connection: innovation, education, and benefits
}

\author{
Larisa Ivascu $^{I^{*}}$, Alin Artene ${ }^{2}$, Attila Turi $^{3}$, Monica Balan ${ }^{4}$ and Corina Dufour ${ }^{5}$ \\ ${ }^{1}$ Politehnica University of Timisoara, Faculty of Management in Production and Transportation, \\ Department of Management, 14 Remus Street, Timisoara, Romania \\ ${ }^{2}$ Politehnica University of Timisoara, Faculty of Management in Production and Transportation, \\ Department of Management, 14 Remus Street, Timisoara, Romania \\ ${ }^{3}$ Politehnica University of Timisoara, Faculty of Management in Production and Transportation, \\ Department of Management, 14 Remus Street, Timisoara, Romania \\ ${ }^{4}$ Politehnica University of Timisoara, Faculty of Management in Production and Transportation, \\ Department of Management, 14 Remus Street, Timisoara, Romania \\ ${ }^{5}$ Politehnica University of Timisoara, Faculty of Management in Production and Transportation, \\ Department of Management, 14 Remus Street, Timisoara, Romania
}

\begin{abstract}
The three responsibilities of the environment, society, and economy are used to model how sustainability can be incorporated into an organization's mission, goals, and practices. There are many worker problems embedded in the concept of sustainability. From the perspective of sustainable development, occupational health and safety (OSH) refers to promoting safety, security, health and welfare of workers. Using an integrated sustainability approach offers a way to rethink worker protection approaches and raises new exploration issues and innovation opportunities. This paper aims to present the connections between OSH and sustainable development taking into account the needs of the economic environment. It focuses on Safety and Health's Core Role in Sustainability. Researchers have also tried to advance the road to sustainable development through innovation and improvement of occupational and health security.
\end{abstract}

\section{Introduction}

Sustainability focuses on leadership, innovation, and goes beyond simplicity of compliance. It also provides a direct link with stakeholders and develops new partnerships. Establishing and applying standards is not enough to prevent millions of workplace injuries and diseases occurring each year. From this perspective, companies should take innovative measures to reduce the number of work-related accidents. The mission of organizations is to get secure jobs. In order to achieve this mission, innovative strategies tailored to current needs and aligned with international approaches are needed. Organizations spend annually billions on sustainability [1-2].

\footnotetext{
${ }^{*}$ Corresponding author: larisa.ivascu@upt.ro
} 
Sustainable development focuses on measurements, reporting, standards and certifications, research, education or investment, but an essential part of sustainability efforts should be the safety and health of workers. Developing a safety culture at work has become a competitive factor for sustainable companies [1-3]. Protecting the safety and health of employees was a requirement set out in the Brundtland Commission report. The report was published in 1987. Organizations have to deal with the management of risks and dangers at work to protect the health and safety of their employees. Employee engagement is one of the fundamental principles of a comprehensive health and safety program. This program helps identify the innovation opportunities for the employer. Employee involvement can improve not only safety and health, but also business performance and education. Employees have in-depth expertise to provide insight into the design and design of products and processes. These actions ultimately have the role of minimizing dangers and improving efficiency [4].

Thus, through an integrated approach to sustainable development and OSH, jobs are becoming safer, more innovative and more sustainable. In the literature, there is little empirical research on planning and control systems for sustainable businesses [5]. Empirical research on the assessment and monitoring of safety and environmental performance is reduced in number in the literature [6].

The objective of this paper is to identify the link between OSH and sustainable development taking into account innovation and education. This paper is structured on: the first part briefly presents the OSH situation, then the link between OSH and sustainability and finally presents the benefits of the OSH - sustainability. Research is based on literature review and empirical research.

\section{Occupational health and safety (OHS)}

OSH promotes and maintains the highest physical, mental and social level for the wellbeing of workers in all organizational occupations. Occupational health issues are particularly important in countries such as Africa and Asia. Africa has insecure working conditions in sectors such as mining, construction, manufacturing and even services. Africa and Asia are described [6-7] as having the most dangerous practices and conditions in managing child labour and employment. Migration, particularly from Africa to Europe, is one that indicates the existence of unsafe and unsustainable practices at work. Existing practices at EU level contribute to the safety and security of the workplace.

There are stable rules and policies that monitor OSH and develop improvement strategies. The number of non-fatal accidents at work in the European Union is increasing compared to 2013. Figure 1 shows that in 2017 there is $10 \%$ more accidents than in 2013. This increase may be due to the development of industries where the number accidents are higher, education / training is inefficient and innovation at work is lacking. 


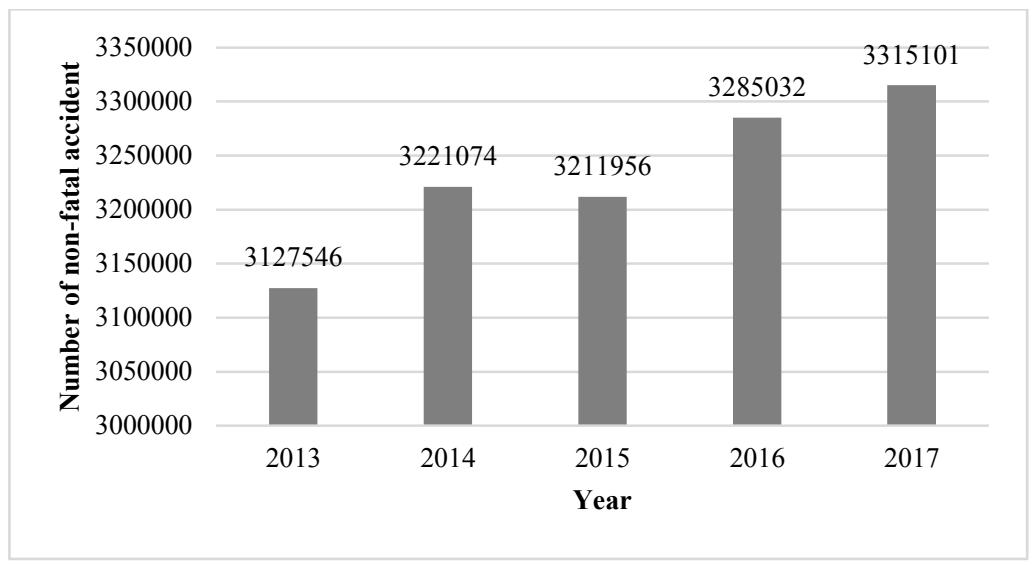

Fig. 1. The situation of non-fatal accidents at the European Union level during the period 2013-2017 [8]

In Romania, Figure 2, the number of non-fatal accidents for the period 2013-2017 follows the situation at EU level. It can be noticed that the year 2017 is the most non-fatal accidents. In 2017, there is a 30\% increase over 2013. Most accidents are recorded in the construction, transport and storage industry, manufacturing and agriculture.

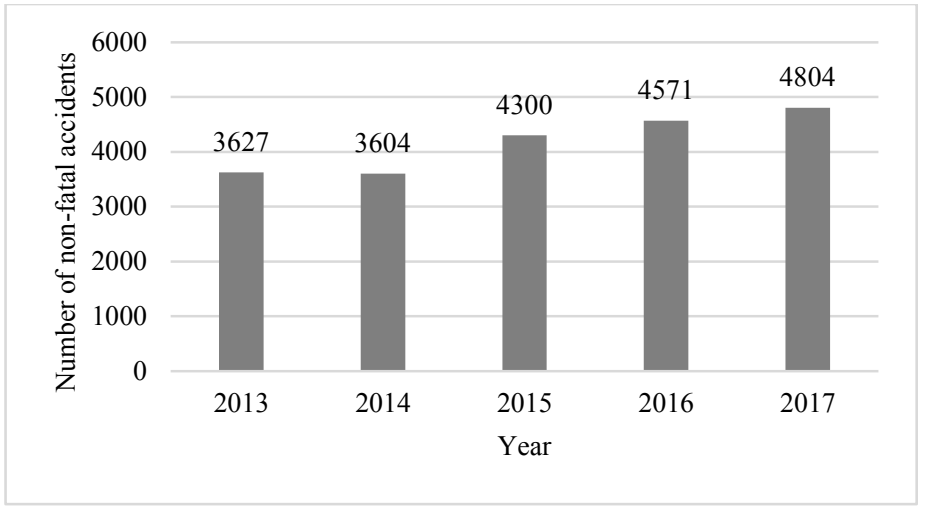

Fig. 2. The situation of non-fatal work accidents in Romania during 2013-2017 [8]

\section{The link between occupational safety and security and sustainability}

Sustainability organizations' concerns have emerged over the past 20 years in response to globalization trends that affect businesses and their ability to provide value for stakeholders. This area of sustainable development is not a new one. It is rather an aggregation of practices, disciplines, education and reporting. Sustainability is undoubtedly of greater importance, as the challenges faced by businesses are evolving. These organizational challenges include workforce and social needs, increased competition for natural resources, increased concern for society over climate change, pollution and nutrition. Organizational concerns are intense for recycling, re-use, renewable energy production, and corporate social responsibility [9]. For security experts, these organizational preoccupations are impressive. But, on the other hand, the security message 
and the Sustainable Development Goal (SDG) refers to the safety of society, and emphasizes less the need to create sustainable jobs. The goal is that if implemented correctly, organizations will create value for their shareholders and customers in an increasingly competitive and complex environment, but will also bring significant value to the communities in which they operate. But companies can only grow sustainably unless they have secure and healthy jobs. The first interference between OSH and susceptibility that can be perceived is that in Figure 3, the $3 \mathrm{P}$ : people, planet, profit. These three entities are strongly integrated into OSH culture. When we talk about people, we talk about safety, health, development. In the same way, when we talk about the planet (environment), we talk about the sustainable economy and the environment. The environment is the place of life, and the working environment is comfortable for people. Finally, when talking about profit (economy), we are talking about the expected result and about a controlled environment (planet) that results in sustainable development. Thus, these three pillars contribute to improving OSH and sustainable development [9-10].

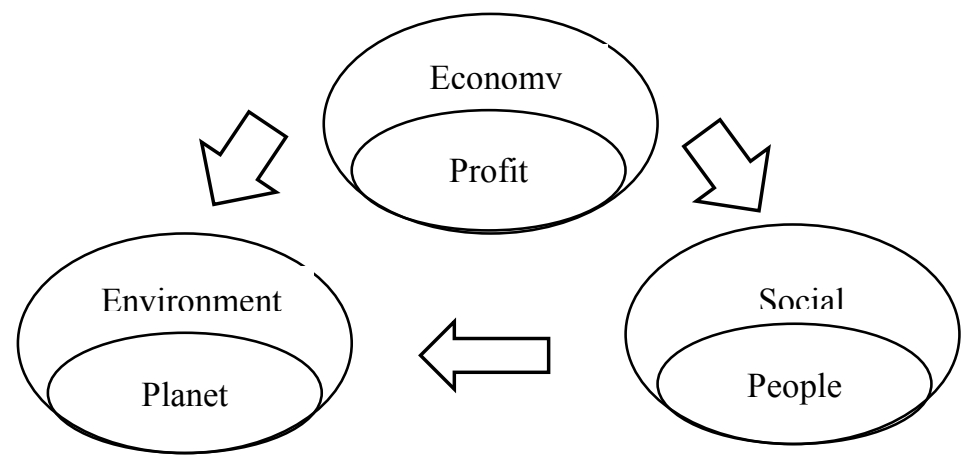

Fig. 3. Important factors of sustainability: profit, planet, people

Figure 4 is a schematic representation of the relationship between OSH and sustainability. This figure highlights the fact that the triple bottom line of sustainability (economic, social and environmental) influences the quality of products and production processes. In turn, it is influenced by organizational culture. At the same time, the development of secure and sustainable jobs is influenced by employee education, the ability of the organization to become competitive and the implementation of sustainable development. Therefore, without the improvement or innovation of safety and health at work, occupational accidents, diseases and costs will not be reduced.

Without taking into account the importance of efficient use of an organization's resources, challenges to health and safety at work cannot end. If the organization fails to control these issues, the result of the profit and the impact on the business environment will not be at the level of the expectations of the stakeholders. Improving OSH contributes to improving production capacity and product quality [6-7]. Sustainable development contributes to the efficient use of resources in production processes. Therefore, sustainable development is an integration of the 3Ps, which are found in the three sustainability responsibilities: economic, social and environmental. 


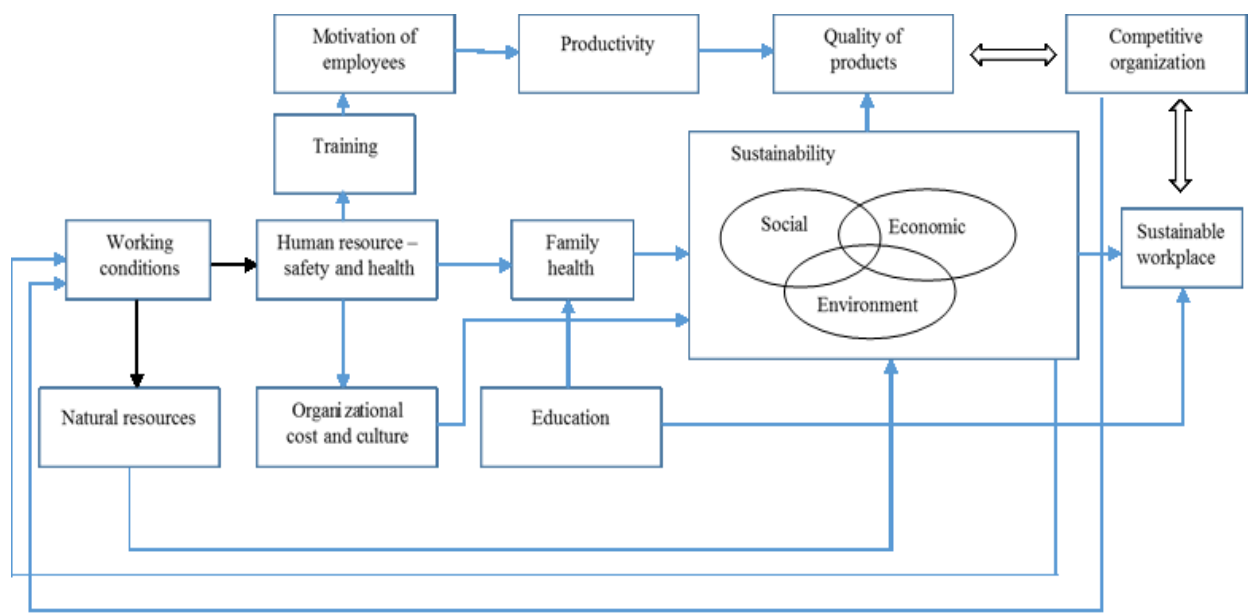

Fig. 4. A model of the link between sustainability and OSH

The integrated approach to OSH and sustainable development contribute to creating safe and sustainable jobs. The two concepts cannot be treated separately [5]. A company cannot grow sustainably if the OSH practices are deficient. On the contrary, a company that has sustainable practices in terms of OSH can become a competitive and sustainable company.

\section{Workplace and innovation: benefits and education}

Safe jobs and healthy employees are the premises for sustainable jobs. The pillars that underpin the development of sustainable [5-6] jobs can be systematized into 6 factors, as follows:

- Improving working condition - is an important step given that the employee is a key element for the organization. If the employee has efficient working conditions, productivity can increase. Efficiency of the economy and improvement of social standards must become a priority for most organizations.

- Workplace innovation and technology - technology is one of the most effective ways to improve working conditions and achieve competitive results.

- Education - Employee education contributes to the understanding and learning of organizational best practices. Continuous employee training can help reduce workrelated accidents. Training courses for employees are directly linked to the creation of sustainable jobs.

- Organizational culture - culture is dynamic, it varies from society to society and requires an analysis of social culture when it comes to improving the working environment. Social culture contributes to the development of organizational culture through its actions for people.

- Improving strategic decisions - stakeholders should take the best strategic decisions for the organization, based on employee health and safety.

- Workplace control - control of workplaces through appropriate techniques and methodologies contributes to reducing occupational risks and increasing job security.

The benefits of developing healthy jobs are outlined in Table 1, divided by the three sustainability (economic, social and environmental) responsibilities. At the same time, the benefits are presented on two important components: innovation and education. 
Table 1. Benefits of the link between OSH and sustainability

\begin{tabular}{|c|l|l|}
\hline Responsibility & \multicolumn{1}{|c|}{ Innovation } & \multicolumn{1}{c|}{ Education } \\
\hline \multirow{3}{*}{ Economic } & $\begin{array}{l}\text { Effective control } \\
\text { Cost reduction } \\
\text { Efficiency of supplier selection process } \\
\text { Reducing losses }\end{array}$ & $\begin{array}{l}\text { Engage trainers for using integrated } \\
\text { programs } \\
\text { Standardizing employee work } \\
\text { Reducing employee negligence }\end{array}$ \\
\hline \multirow{5}{*}{ Envial } & $\begin{array}{l}\text { Improving stakeholder relations } \\
\text { Improve public image } \\
\text { Improving employee work } \\
\text { Reducing overworking of employees }\end{array}$ & $\begin{array}{l}\text { Increase communication level } \\
\text { Improving communication techniques } \\
\text { Increasing the number of candidates } \\
\text { in the interview process }\end{array}$ \\
\hline & $\begin{array}{l}\text { Reducing the negative impact on the } \\
\text { environment } \\
\text { Increase reuse } \\
\text { The introduction of innovative concepts } \\
\text { contributes to reducing the amount of } \\
\text { gas generated }\end{array}$ & $\begin{array}{l}\text { Employee involvement in corporate } \\
\text { social responsibility actions } \\
\text { Increasing health at work } \\
\text { Reducing stress at work }\end{array}$ \\
\hline
\end{tabular}

\section{Conclusions and discussion}

In conclusion, this paper aims to show the link between OSH and sustainability. Sustainable development cannot be taken into account separately, without taking into account workplace, safety and health improvement, reducing accidents and occupational diseases, workplace education, workplace innovation, safety and health, environmental control. The organization's financial results and sustainable development are interconnected parameters. Environment and society are considered key elements for increasing competitiveness [11-12]. A new organizational management style and innovative systems for improving safety and health at work are important pillars in organizational development. Increasing levels of education and employee interest contribute to reducing the negative impact on the environment and implicitly improving the quality of life. The long-term effects of culture, technology and politics are rooted in sustainable development in terms of safety and health at work.

This work was supported in part by research grant GNaC2018-ARUT, no. 1359/01.02.2019, financed by Politehnica University of Timisoara.

\section{References}

1. N. Duijm, C. Fiévez, M. Gerbec, U. Hauptmanns, M. Konstandinidou, Management of health, safety and environment in process industry, Saf. Sci. 46, 908-920 (2008)

2. H. Nordlöf, B. Wiitavaara, H. Högberg, R. Westerling, A cross-sectional study of factors influencing occupational health and safety management practices in companies, Saf. Sci. 95, 92-103 (2017)

3. Z. Guiras, S. Turki, N. Rezg, A. Dolgui, Optimal maintenance plan for two-level assembly system and risk study of machine failure, Int. J. Product. Res., 1-18 (2018)

4. B.O. Alli, Fundamental Principles of Occupational Health and Safety, International Labour Office, Geneva (2008)

5. A. Gaureanu, A. Draghici, A. Mateescu, H. Weinschrott, Gaps and directions to improve occupational safety and health training programs in Romania (2016)

6. A. Draghici, M. Mocan, G. Draghici, On-Line Training and Certification Solution for Business Process Managers, International Conference on Enterprise Information Systems, Communications in Computer and Information Science, 219, 380 (2011) 
7. L. Ivascu, B. Cirjaliu, A. Draghici, Business model for the university-industry collaboration in open innovation, 3rd Global Conference on Business, Economics, Management and Tourism, Procedia Economics and Finance, 39, 674 (2016)

8. National Intitute of Statistics, Available at www.insse.ro (accesed on 01 February 2019)

9. S. Boini, R. Colin, M. Grzebyk, Effect of occupational safety and health education received during schooling on the incidence of workplace injuries in the first 2 years of occupational life: a prospective study. BMJ Open 7 (2017)

10. N. M. Shamsudin, N. Hasnaa, N. Mahmood, N. M. Shamsudin, N. H. N. Mahmood, Occupational Safety and Health (OSH) Training: A Meta Analysis on the Learner's Characteristics for Young and Aging Malaysian Workforce. Technol. Soc. Sci. 999-1006 (2014). doi:10.1007/978-981-10-1458-1_90

11. E.C. Rada, L. Cioca, Optimizing the Methodology of Characterization of Municipal Solid Waste in EU Under a Circular Economy Perspective, International Conference on Technologies and Materials for Renewable Energy, Environment and Sustainability (TMREES), vol. 119, 72-85 (2017)

12. L.-I. Cioca, M. Cioca, Using distributed programming in production system management, WSEAS Transactions on Information Science and Applications, 4(2), pp. 303-308 (2017) 